\title{
MELANOMA MALIGNO METASTÁTICO EM CAVIDADE BUCAL: RELATO DE CASO CLÍNICO
}

Jean Felipe Garlet WERLANG, Vanessa Sanglard de SOUZA, Cassius Torres PEREIRA, Cleto Mariosvaldo PIAZZETTA, José Miguel AMENÁBAR

O melanoma é neoplasia maligna de origem dos melanócitos. Embora represente apenas $4 \%$ dos tipos de câncer de pele é o mais grave devido à sua alta possibilidade de metástase, tornando-o altamente letal, porém com prognóstico bom se detectado nos estádios iniciais. Os melanomas em boca são muito raros e metástases no complexo maxilo-mandibular são mais raros ainda. Esse trabalho relata um caso de melanoma metastático, levando em conta a importância de um diagnóstico precoce diante de uma lesão tão rara e de prognóstico ruim. Uma paciente de sexo feminino, 33 anos, leucoderma, se apresentou com queixa de aumento de volume na gengiva do lado direito inferior com parestesia no lábio direito. Durante a anamnese foi constatada o diagnóstico de melanoma maligno polipóide $\mathrm{pT} 3 \mathrm{bNxMx}$ dorsal, com presença de linfonodo sentinela e metástase em linfonodo dorsal. Ao exame físico intrabucal, foi observada uma lesão ulcerada no rebordo alveolar direito inferior, fundo escuro, bordas elevadas, firme à palpação, assintomática, com evolução de 30 dias. A radiográfica panorâmica revela área radiolúcida na região do 48 . Foi realizada uma biópsia incisional da lesão com hipótese diagnóstica de metástase de melanoma, sendo confirmado pelo exame anatomopatológico. A paciente foi encaminhada para 0 oncologista e encontra-se em acompanhamento.

Palavras chave: melanoma; neoplasias bucais; estomatologia. 